J. Lake Sci. (湖泊科学) , 2016, 28(6): 1235-1243

DOI 10. 18307/2016. 0609

(C) 2016 by Journal of Lake Sciences

\title{
气象条件对淀山湖水质的影响”
}

张德林 ${ }^{1}$, 陆佳麟 ${ }^{1}$, 张佳婷 $^{1}$, 季旻骊 $^{1}$, 黄慧慧 $^{2}$

(1: 上海市青浦区气象局,上海 201700)

(2: 上海市青浦区水文勘测队,上海 201700)

摘 要: 根据 2007-2014 年淀山湖湖体每月高镇酸盐指数 $\left(\mathrm{COD}_{\mathrm{Mn}}\right)$ 、氨氮 $\left(\mathrm{NH}_{3}-\mathrm{N}\right)$ 、总氮 $(\mathrm{TN})$ 和总磷 $(\mathrm{TP})$ 等水质资料 和青浦区气象局月平均气温、降水量和日照时数等气象资料, 运用数理统计方法和特征值比较法分析淀山湖湖体 $\mathrm{COD}_{\mathrm{Mn}} 、 \mathrm{NH}_{3} \mathrm{-N}$ 、TN 和 TP 等水质资料变化规律及温度、降水和日照时数等对水质的影响. 结果表明: (1) 气象条件影响淀 山湖湖体水质. 平均气温、日照时数影响 $\mathrm{NH}_{3}-\mathrm{N} 、 \mathrm{TN}$ 和 $\mathrm{TP}$ 浓度, 表现在平均气温高、日照时数多, $\mathrm{NH}_{3}-\mathrm{N} 、 \mathrm{TN}$ 浓度降低, 相 反平均气温低、日照时数少, $\mathrm{NH}_{3}-\mathrm{N} 、 \mathrm{TN}$ 浓度升高; 平均气温高, 也会使 $\mathrm{TP}$ 浓度上升, 平均气温低, TP 浓度降低. 降水对水 体中 $\mathrm{COD}_{\mathrm{Mn}} 、 \mathrm{NH}_{3}-\mathrm{N}$ 和 $\mathrm{TN}$ 等浓度有稀释作用, 降水量多的月份其浓度偏低, 相反降水量少的月份其浓度偏高. (2) 受气 象条件影响, $\mathrm{COD}_{\mathrm{Mn}} 、 \mathrm{NH}_{3}-\mathrm{N} 、 \mathrm{TN}$ 和 TP 有季节变化. $\mathrm{COD}_{\mathrm{Mn}}$ 浓度 4-9 月较高, 10 月一翌年 3 月较低; $\mathrm{NH}_{3}-\mathrm{N} 、 \mathrm{TN}$ 浓度最高 值出现在 2-4 月前后, 最低值出现在 7-10 月; TP 浓度最高值出现在 7-8 月, 最低值出现在 10 月一翌年 5 月. (3) 淀山 湖 $\mathrm{COD}_{\mathrm{Mn}} 、 \mathrm{NH}_{3}-\mathrm{N}$ 、TN 和 TP 浓度呈下降趋势.

关键词: 气象条件;淀山湖; 水质

\section{Effects of meteorological factors on the water quality of Lake Dianshan}

\author{
ZHANG Delin ${ }^{1}$, LU Jialin ${ }^{1}$, ZHANG Jiating ${ }^{1}$, JI Minli ${ }^{1} \&$ HUANG Huihui ${ }^{2}$ \\ (1: Qingpu Meteorolgical Office of Shanghai, Shanghai 201700, P.R.China) \\ (2: Hydrological Survey Team of Shanghai Qingpu District, Shanghai 201700, P.R.China)
}

\begin{abstract}
According to the monthly monitoring data on water quality (permanganate index $\left(\mathrm{COD}_{\mathrm{Mn}}\right)$, ammonia nitrogen $\left(\mathrm{NH}_{3}-\mathrm{N}\right)$, total nitrogen ( TN), total phosphorus ( TP ) ) and meteorologicalogy ( mean temperature, precipitation, sunshine duration) from 2007 to 2014, the change pattern of water quality in Lake Dianshan and the impacts from meteorological factors were analyzed. Results showed that: 1) Mean temperature and sunshine duration had significantly negative impacts on $\mathrm{NH}_{3}-\mathrm{N}$ and TN. Mean temperature had significantly positive impacts on TP. Precipitation diluted and had negative impacts on $\mathrm{COD}_{\mathrm{Mn}}, \mathrm{NH}_{3}-\mathrm{N}$ and TN. 2) Water quality exhibited seasonal variations under the meteorological impact. Higher values of $\mathrm{COD}_{\mathrm{Mn}}$ appeared between April and September, while lower values between October and March. $\mathrm{NH}_{3}-\mathrm{N}$, TN peaked between February and April, reaching lowest value between July and October. TP peaked during July and August, while lower values appeared between October and May. 3 ) COD ${ }_{\mathrm{Mn}}$, $\mathrm{NH}_{3}-\mathrm{N}, \mathrm{TN}$, TP showed downward trends.
\end{abstract}

Keywords: Meteorological factors; Lake Dianshan; water quality

湖泊作为一种重要的自然资源, 具有蓄水、供水、航运、旅游和养殖等多项生态功能. 由于人类活动强度 的不断增强以及自然环境的变化, 湖泊水质环境受到严重威胁 ${ }^{[1]}$, 许多学者对河流、水库、湖泊水质进行了 研究 ${ }^{[2-8]}$. 在河湖、水库水质变化与气象条件关系方面也有学者进行了研究, 盛海燕等 ${ }^{[9]}$ 分析新安江水库近 10 年水质演变趋势及与水文气象因子的关系, 表明降水量与溶解氧、总磷 (TP)、氨氮浓度呈显著正相关,气 温与水温、 $\mathrm{pH}$ 值、高锰酸盐指数 $\left(\mathrm{COD}_{\mathrm{Mn}}\right)$ 、五日生化需氧量 $\left(\mathrm{BOD}_{5}\right) 、 \mathrm{TP}$ 和叶绿素 $\mathrm{a}(\mathrm{Chl} . \mathrm{a})$ 浓度呈显著正相 关; 许梅等 ${ }^{[10]}$ 对位于太湖西部宜兴市的一条人湖河流水质的年变化规律进行分析, 表明水体中 $\mathrm{BOD}_{5}$ 、

* 上海市气象局科技开发项目(S201417) 资助. 2015-05-26 收稿;2016-01-14 收修改稿. 张德林( 1962 ), 男, 高 级工程师;E-mail: zdl_qp@ 163.com. 
$\mathrm{COD}_{\mathrm{Mn}}$ 、Chl. a 浓度的变化主要受温度的影响, 温度变化是水体有机质含量变化的触发因子; 降雨量与水体 $\mathrm{TP}$ 浓度呈显著正相关,但对其他水质指标影响较小; 高伟等 ${ }^{[1]}$ 研究抚仙湖 $\mathrm{COD}_{\mathrm{Mn}} 、 \mathrm{TP}$ 、总氮 ( TN ) 、Chl. a 、透 明度和浮游植物丰度等水质指标的变化, 认为人口数量和水温是水质变化的主要驱动因子; 刘梅等 ${ }^{[11]}$ 研究 认为, 因气温上升导致水体温度升高, 增强了微生物的活性, 进而促进底泥中内源氮、磷的释放, 降水少致径 流减少, 径流的减少降低了水体的稀释能力, 对磷而言径流的减少将会减少陆地磷污染物进人水体. 淀山湖 主要承受东太湖和苏州淀泖地区来水, 其人湖污染源为上游来水带来的污染负荷和本地各种污染排放, 气 温、降水量等影响淀山湖水质, 本文根据淀山湖湖体 $\mathrm{COD}_{\mathrm{Mn}}$ 、氨氮 $\left(\mathrm{NH}_{3}-\mathrm{N}\right) 、 \mathrm{TP} 、 \mathrm{TN}$ 等水质资料和青浦区气 象局等月平均气温、降水量、日照时数等资料, 研究这些水质指标变化与气象条件的关系, 从而为开展水文 气象业务服务提供技术支持.

\section{1 淀山湖区域概况}

淀山湖 $\left(31^{\circ} 04^{\prime} \sim 31^{\circ} 12^{\prime} \mathrm{N}, 120^{\circ} 53^{\prime} \sim 121^{\circ} 01^{\prime} \mathrm{E}\right)$ 是太湖流域第二大省界湖泊, 位于太湖流域下游, 上海市 的西部, 距上海市区 50 余 $\mathrm{km}$, 地处江苏省昆山市、吴江市和上海市青浦区交界处. 湖泊面积 $62 \mathrm{~km}^{2}$, 平均水 深 $2.1 \mathrm{~m}$, 最大水深 $3.59 \mathrm{~m}$. 淀山湖是上海境内最大的天然淡水湖泊, 是黄浦江上游来水水源之一, 其水环境 状况直接关系着周围区域的水环境、水生态安全及下游的上海市黄浦江上游水源地的水质安全. 淀山湖主 要承受东太湖和苏州淀泖地区来水, 主要入湖河流为千灯浦、大朱厍、急水港和元荡, 主要出湖河流为拦路 港、淀浦河等(图 1). 淀山湖人湖污染源为上游来水带来污染负荷和本地工业污染、农业农村面源污染、城 镇污染等排放.

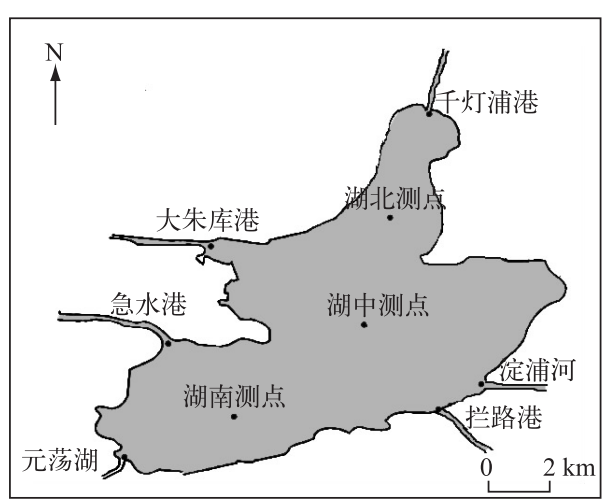

图 1 淀山湖地理位置和断面、监测点分布

Fig.1 Situation and distribution of rivers and monitoring sites in Lake Dianshan

\section{2 资料和方法}

\section{1 资料来源}

2006 年 11 月-2014 年 11 月温度、降水量、日照时数 等气象观测资料来源于青浦区气象局; 2007 年 1 月2013 年 12 月温度、降水量、日照时数等气象观测资料来 源于吴江、吴中、昆山、东山、湖州、嘉兴等气象局. 2007 年 1 月- 2014 年 11 月 $\mathrm{COD}_{\mathrm{Mn}} 、 \mathrm{NH}_{3}-\mathrm{N} 、 \mathrm{TN} 、 \mathrm{TP}$ 水质资料 来源于太湖流域水资源保护局发布的《太湖流域及东南 诸河省界水体水资源质量状况通报》. 按《地表水环境质 量标准》(GB 3838-2002) 将水质分为 $\mathrm{V}$ 类, 水质超过 $\mathrm{V}$ 类标准限值时称为劣 $\mathrm{V}$ 类.

\section{2 方法}

太湖流域水环境监测中心每月对淀山湖 3 个监测点 (分别位于淀山湖南部、中部、北部) 进行水质监测. 水质

评价采用单因子评价法, 标准采用《地表水环境质量标准》(GB 3838-2002), 评价项目为水温、 $\mathrm{pH}$ 值、溶解 氧 (DO)、 $\mathrm{COD}_{\mathrm{Mn}}$ 、化学需氧量、 $\mathrm{BOD}_{5} 、 \mathrm{NH}_{3}-\mathrm{N} 、 \mathrm{TP} 、 \mathrm{TN} 、$ 铜、锌、氟化物、硒、砷、采、镉、铬(六价)、铅、氧化物、挥 发酚、石油类、阴离子表面活性剂 (LAS) 和硫化物共 23 项.

淀山湖主要承受东太湖和苏州淀泖地区来水, 上游地区的气温、降水量、日照时数等也会影响淀山湖上 游来水的水质. 分析 2007 年 1 月 -2013 年 12 月吴江、吴中、昆山、东山、湖州、嘉兴等气象局月平均气温、月 降水量和月日照时数与青浦区气象局月平均气温、月降水量和月日照时数相关关系 (表 1), 月平均气温相关 系数均 $>0.999$, 月降水量相关系数 $>0.829$, 月日照时数相关系数 $>0.928$; 并且各地方月平均气温、月降水量和 月日照时数的最小值、最大值和平均值都比较接近. 因此本文中东太湖和苏州淀泖地区气象资料用青浦区 气象局月平均气温、月降水量、月日照时数代表. 
表 1 各站点气象要素值及相关系数

Tab.1 Meteorological factors and correlations beteewn Qinpu and others

\begin{tabular}{|c|c|c|c|c|c|c|c|c|}
\hline 要素 & & 青浦 & 吴江 & 吴中 & 昆山 & 东山 & 湖州 & 嘉兴 \\
\hline \multirow[t]{3}{*}{ 月平均气温 $/{ }^{\circ} \mathrm{C}$} & 最小值 & 0.7 & 0.9 & 1.1 & 1.0 & 0.5 & 0.3 & 0.9 \\
\hline & 最大值 & 32.2 & 32.0 & 32.3 & 31.8 & 31.7 & 31.8 & 31.4 \\
\hline & 平均值 & 17.2 & 17.3 & 17.3 & 17.1 & 16.9 & 16.8 & 16.9 \\
\hline 与青浦相关系数 & & & 0.9993 * & 0.9991 * & 0.9991 * & 0.9992 * & $0.9994^{*}$ & $0.9995^{*}$ \\
\hline \multirow[t]{3}{*}{ 月降水量/mm } & 最小值 & 9.6 & 4.0 & 2.9 & 1.6 & 4.6 & 9.1 & 9.1 \\
\hline & 最大值 & 323.4 & 374.5 & 328.2 & 363.7 & 381.8 & 397.5 & 350.4 \\
\hline & 平均值 & 89.8 & 96.9 & 91.2 & 97.3 & 97.1 & 105.0 & 103.0 \\
\hline 与青浦相关系数 & & & $0.8886^{*}$ & 0.9127 * & 0.8291 * & $0.8843^{*}$ & 0.8421 * & 0.8872 * \\
\hline \multirow[t]{3}{*}{ 月日照时数/h } & 最小值 & 47.5 & 51.7 & 48.7 & 45.1 & 53.6 & 54.8 & 53.9 \\
\hline & 最大值 & 277.0 & 316.6 & 321.5 & 301.7 & 327.0 & 305.7 & 297.5 \\
\hline & 平均值 & 137.0 & 159.6 & 155.5 & 148.7 & 173.6 & 159.1 & 154.9 \\
\hline 与青浦相关系数 & & & $0.9583^{*}$ & $0.9402 *$ & $0.9344^{*}$ & $0.9283^{*}$ & $0.9494^{*}$ & 0.9444 * \\
\hline
\end{tabular}

* 表示通过 $\alpha=0.01$ 信度检验.

各气象 (青浦区气象局观测资料)、水质资料 的统计量见表 2 .

\section{3 结果与分析}

\section{1 淀山湖水质变化特征及时间序列趋势}

淀山湖 2007 年 1 月 - 2014 年 11 月 $\mathrm{COD}_{\mathrm{Mn}_{\mathrm{n}}}$ 浓度变化幅度较大, 在 $3.67 \sim 10.00 \mathrm{mg} / \mathrm{L}$ 之间, 为 II 类 IV 类水标准; 平均值为 $5.02 \mathrm{mg} / \mathrm{L}$, 为 III 类 水标准. $\mathrm{COD}_{\mathrm{Mn}}$ 浓度存在季节变化, $4-9$ 月浓度 较高, 而 10 月一翌年 3 月浓度较低.

$\mathrm{NH}_{3}-\mathrm{N}$ 浓度变化幅度很大, 在 $0.05 \sim 6.20$ $\mathrm{mg} / \mathrm{L}$ 之间, 为 $\mathrm{I} \sim$ 劣 $\mathrm{V}$ 类水标准; 平均值为 1.26 $\mathrm{mg} / \mathrm{L}$, 为 $\mathrm{IV}$ 类水标准. $\mathrm{NH}_{3}-\mathrm{N}$ 浓度 $>2 \mathrm{mg} / \mathrm{L}$ 的劣
表 2 气象、水质资料的统计量 ${ }^{*}$

Tab.2 Summary of statistics of meteorological variables and water quality

\begin{tabular}{lccccc}
\hline 指标 & 数据量 & 最小值 & 最大值 & 平均值 & 方差 \\
\hline 月平均气温 $/{ }^{\circ} \mathrm{C}$ & 97 & 0.9 & 31.2 & 16.7 & 74.6 \\
月降水量 $/ \mathrm{mm}$ & 97 & 6.1 & 323.4 & 91.7 & 4422.0 \\
月日照时数 $/ \mathrm{h}$ & 97 & 47.5 & 264.6 & 134.0 & 2346.3 \\
$\mathrm{COD}_{\mathrm{Mn}} /(\mathrm{mg} / \mathrm{L})$ & 95 & 3.67 & 10.00 & 5.02 & 0.90 \\
$\mathrm{NH}_{3}-\mathrm{N} /(\mathrm{mg} / \mathrm{L})$ & 95 & 0.05 & 6.20 & 1.26 & 1.46 \\
$\mathrm{TN} /(\mathrm{mg} / \mathrm{L})$ & 95 & 1.73 & 9.82 & 4.16 & 2.59 \\
$\mathrm{TP} /(\mathrm{mg} / \mathrm{L})$ & 95 & 0.071 & 0.314 & 0.150 & 0.003 \\
\hline
\end{tabular}

* 数据量和方差无单位.

$\mathrm{V}$ 类水,共出现 13 次,主要集中在 2009 年 3 月以前的时段; 而 $\leqslant 0.15 \mathrm{mg} / \mathrm{L}$ 的 I 类水,共出现 5 次, 主要集中 在 2013 年 10 月以后的时段. $\mathrm{NH}_{3}-\mathrm{N}$ 浓度的季节变化比较明显, 一年中高峰值出现在 $2-4$ 月, 而低谷值出现 在 7-10月.

$\mathrm{TN}$ 浓度变化幅度在 $1.73 \sim 9.82 \mathrm{mg} / \mathrm{L}$ 之间, 为 $\mathrm{V}$ 类和劣 $\mathrm{V}$ 类水标准; 平均值为 $4.16 \mathrm{mg} / \mathrm{L}$, 为劣 $\mathrm{V}$ 类水标 准. 淀山湖 TN 浓度居高不下,除 2014 年 9 月 ( $1.84 \mathrm{mg} / \mathrm{L}) 、 10$ 月 (1.73 mg/L) 为 V 类水标准外, 其余都> 2.0 $\mathrm{mg} / \mathrm{L}$, 为劣 $\mathrm{V}$ 类水标准, 是 4 个指标中最严重的指标. $\mathrm{TN}$ 浓度的季节变化也比较明显, 一年中高峰值出现在 $2-4$ 月,而低谷值出现在 7-10月.

$\mathrm{TP}$ 浓度变化幅度在 $0.071 \sim 0.314 \mathrm{mg} / \mathrm{L}$ 之间, 为 $\mathrm{V}$ 类 劣 $\mathrm{V}$ 类水标准; 平均值为 $0.15 \mathrm{mg} / \mathrm{L}$, 为 $\mathrm{V}$ 类水标 准. $\mathrm{TP}$ 浓度 $>0.2 \mathrm{mg} / \mathrm{L}$ 的劣 $\mathrm{V}$ 类水标准,共出现 14 次,占 $14.7 \% ; 0.1 \mathrm{mg} / \mathrm{L}<\mathrm{TP}$ 浓度 $\leqslant 0.2 \mathrm{mg} / \mathrm{L}$ 的 $\mathrm{V}$ 类水标 准, 共出现 71 次, 占 $74.7 \% ; 0.05 \mathrm{mg} / \mathrm{L}<\mathrm{TP}$ 浓度 $\leqslant 0.1 \mathrm{mg} / \mathrm{L}$ 的 $\mathrm{IV}$ 类水标准,共出现 10 次, 仅占 $10.5 \%$. 可见淀 山湖 TP 浓度居高不下. TP 浓度存在季节变化, 高峰值出现在 $7 、 8$ 月; 低谷值出现在 10 月一翌年 5 月, 多数 年份低谷值出现在 $4-5$ 月.

采用 Mann-Kendall 检验方法,计算 2007 年 1 月-2014 年 11 月淀山湖 4 项水质指标时间序列趋势的检 验值, 结果表明 $\mathrm{COD}_{\mathrm{Mn}} 、 \mathrm{NH}_{3}-\mathrm{N} 、 \mathrm{TN}$ 浓度均通过 $\alpha=0.01$ 显著性水平上 $\mathrm{M}-\mathrm{K}$ 检验, 均有极显著的下降趋势; 而 $\mathrm{TP}$ 浓度通过 $\alpha=0.05$ 显著性水平检验, 有显著下降趋势. 淀山湖 $\mathrm{COD}_{\mathrm{Mn}} 、 \mathrm{NH}_{3}-\mathrm{N} 、 \mathrm{TN}$ 和 $\mathrm{TP}$ 浓度降低, 这主要 

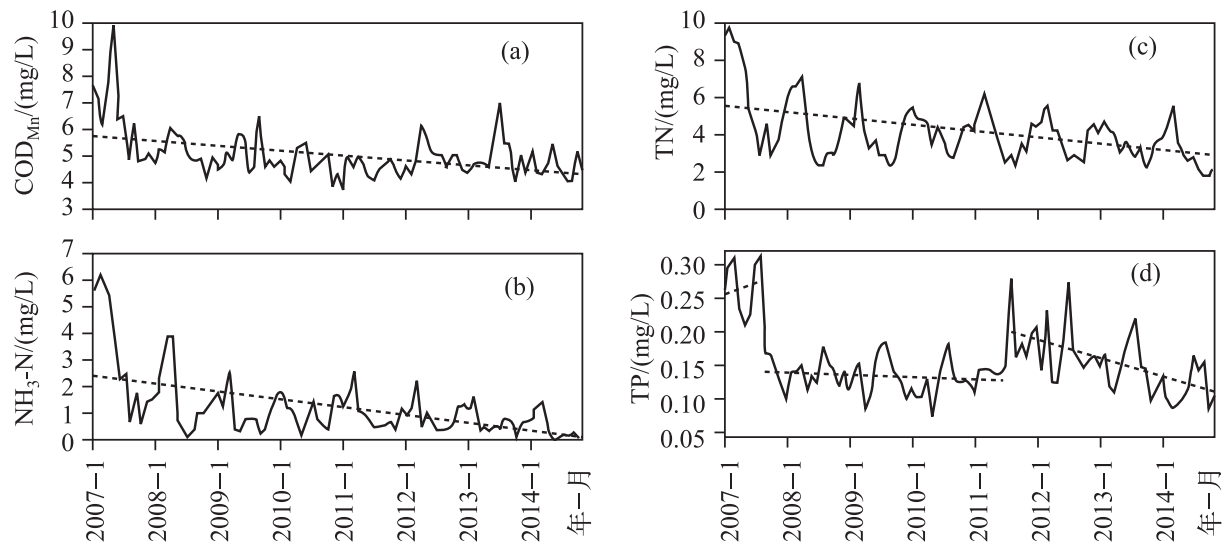

图 2 淀山湖 $\mathrm{COD}_{\mathrm{Mn}}(\mathrm{a}) 、 \mathrm{NH}_{3}-\mathrm{N}(\mathrm{b}) 、 \mathrm{TN}(\mathrm{c})$ 和 $\mathrm{TP}(\mathrm{d})$ 浓度变化 (虚线为趋势线)

Fig.2 Variations of $\mathrm{COD}_{\mathrm{Mn}}(\mathrm{a}), \mathrm{NH}_{3}-\mathrm{N}(\mathrm{b}), \mathrm{TN}(\mathrm{c})$ and $\mathrm{TP}(\mathrm{d})$ concentrations in Lake Dianshan (broken line denote trend line)

得益于 2008 年起江、浙、沪地区实施太湖流域水环境综合治理成果.

\section{2 淀山湖水质指标与气象要素相关性分析}

统计淀山湖 $\mathrm{COD}_{\mathrm{Mn}} 、 \mathrm{NH}_{3}-\mathrm{N} 、 \mathrm{TN}$ 和 TP 浓度变化与月平均气温、降水量、日照时数的相关性, 月平均气温、降 水量、日照时数分为当月、上月和上 2 个月; 并给定显著性水平 $\alpha=0.05$, 样本数 $n=95$, 进行检验 (表 3 ). $\mathrm{NH}_{3}-\mathrm{N}$ 、 $\mathrm{TN}$ 浓度与平均气温、降水量和日照时数呈显著负相关 $(\alpha<0.05)$; TP 浓度与平均气温呈显著正相关 $(\alpha<0.05)$.

表 3 水质指标与气象要素的相关系数

Tab.3 Correlation beteewn water quality and meteorological factors

\begin{tabular}{lrlrl}
\hline 气象要素 & $\mathrm{COD}_{\mathrm{Mn}}$ & $\mathrm{NH}_{3}-\mathrm{N}$ & $\mathrm{TN}$ & $\mathrm{TP}$ \\
\hline 当月平均气温 & 0.1731 & $-0.3829^{*}$ & $-0.5364^{*}$ & $0.2857^{*}$ \\
当月降水量 & -0.0890 & $-0.2189^{*}$ & $-0.2423^{*}$ & 0.0788 \\
当月日照时数 & 0.1499 & -0.1413 & -0.1865 & 0.1011 \\
上月平均气温 & -0.0109 & $-0.4521^{*}$ & $-0.6624^{*}$ & $0.2343^{*}$ \\
上月降水量 & -0.0077 & $-0.3178^{*}$ & $-0.4135^{*}$ & 0.0650 \\
上月日照时数 & 0.0669 & -0.1695 & $-0.2335^{*}$ & -0.0204 \\
上 2 个月平均气温 & -0.0817 & $-0.4442^{*}$ & $-0.6704^{*}$ & 0.1955 \\
上 2 个月降水量 & 0.0098 & $-0.4076^{*}$ & $-0.5500^{*}$ & 0.0664 \\
上 2 个月日照时数 & 0.0325 & $-0.2279^{*}$ & $-0.3140^{*}$ & -0.0780 \\
\hline
\end{tabular}

* 为通过 $\alpha=0.05$ 信度检验.

\section{4 讨论}

气温通过大气与水接触面的热量交换、辐射等方式传递热量, 从而影响水温; 水温随着气温变化, 气温 升高水温也升高, 反之则水温降低, 因此水温基本会与附近气温相一致. 温度对水质影响表现在, 水温升高 将提高水体中污染物离子活跃程度, 提高离子浓度、加快水体中化学反应速率, 水温升高也会增强微生物的 活性从而促进底泥中内源性氮和磷的释放 ${ }^{[11-14]}$, 增加 $\mathrm{COD}_{\mathrm{Mn}} 、 \mathrm{NH}_{3}-\mathrm{N} 、 \mathrm{TN}$ 和 TP 浓度.

温度和光照影响水生植物光合作用和生长 ${ }^{[10,15-20]}$, 而水生植物能吸收水体中的氮、磷 ${ }^{[21-27]}$, 随着温度上 升, 日照时数延长、光照增强, 水生植物生长旺盛, 吸收、降解水体中的氮就多, 使得水体中氮浓度下降; 水生 植物光合作用能产生氧气, 增加水体中的溶解氧, 从而改善水质. 而研究表明 ${ }^{[24-25]}$, 从水生植物对氮、磷降解 
贡献率的比较来看, 氮的降解贡献率要明显高于磷, 因为水中磷的去除除了植物吸收外只有依靠底质和根 系吸附去除, 而氮的去除还有氨的挥发、硝化和反硝化等途径, 水生植物能输送氧气到根区, 为微生物的硝 化和反硝化提供适宜条件, 从而提高水体中氮的去除效率, 因此水生植物对氮的吸收、降解要高于对磷的吸 收、降解.

降水对水质的影响表现在,降水量是驱动面源污染物人湖的最重要因素之一 ${ }^{[1]}$, 雨水所形成的径流经 过地面, 尤其是农田、工业用地附近,地面积聚的污染物被冲刷进人河流或湖泊,造成水体污染; 而水体中的 磷主要来自于土壤颗粒, 通过降水、排水产生的径流流人河湖 ${ }^{[10]}$, 使水体中有机物、无机还原性物质、氮、磷 等浓度增加; 降水形成的大气湿沉降使大气中污染物随降水落人河流或湖泊. 另一方面,降水量流人河湖, 可以稀释水体中污染物浓度, 尤其是连续性大的降水量, 能降低水体中有机物、无机还原性物质、 $\mathrm{NH}_{3}-\mathrm{N}$ 和 $\mathrm{TN}$ 等浓度。

\section{1 气象条件对 $\mathrm{COD}_{\mathrm{Mn}}$ 的影响}

随温度上升水体中污染物离子活跃程度增强, 加快水体中化学反应速率, $\mathrm{COD}_{\mathrm{Mn}}$ 浓度也随之提高, 因此 气温较高的夏半年, 是 $\mathrm{COD}_{\mathrm{Mn}}$ 浓度偏高的时段; 而 气温较低的冬半年是 $\mathrm{COD}_{\mathrm{Mn}}$ 浓度偏低的时段; 但 温度对 $\mathrm{COD}_{\mathrm{Mn}}$ 浓度的影响有限,一年中 $\mathrm{COD}_{\mathrm{Mn}}$ 浓 度的峰点并不出现在最热的 $7 、 8$ 月,谷点也不出 现在最冷的 $1 、 2$ 月; $\mathrm{COD}_{\mathrm{Mn}}$ 与平均气温相关性不 显著 (表 3 ). 盛海燕、华呈平等研究认为,气温与 水温、 $\mathrm{COD}_{\mathrm{Mn}}$ 浓度均呈显著性正相关 ${ }^{[9,28]}$, 而曹金 玲等认为, 年平均气温与 $\mathrm{COD}_{\mathrm{Mn}}$ 呈显著负相关 ${ }^{[29]}$. 因此温度对不同水库、湖泊的 $\mathrm{COD}_{\mathrm{Mn}}$ 浓度影响 不同.

降水所形成的径流将污染物被冲刷进人河流 或湖泊,造成水体污染, 增加水体中 $\mathrm{COD}_{\mathrm{Mn}}$ 浓度; 而大的降水量流人河湖, 可以稀释水体中污染物 浓度, 其对浓度稀释能力远强于径流所增加的浓 度; 相反降水量少容易使水体中 $\mathrm{COD}_{\mathrm{Mn}}$ 浓度升高. 降水量多的月份 $(\geqslant 180 \mathrm{~mm})$, 绝大部分月份 $\mathrm{COD}_{\mathrm{Mn}} \leqslant 5 \mathrm{mg} / \mathrm{L}$, 未出现过 $\geqslant 6 \mathrm{mg} / \mathrm{L}$ 月份, 而且浓 度一般比上月明显下降; 降水量少的月份 $(\leqslant 90$ $\mathrm{mm}), \mathrm{COD}_{\mathrm{Mn}}$ 一般 $\geqslant 5 \mathrm{mg} / \mathrm{L}$, 而且浓度比上月明显 上升 (表 4,图 3). 尽管 $\mathrm{COD}_{\mathrm{Mn}}$ 浓度变化与降水量 相关性不显著, 但大的降水对水体中 $\mathrm{COD}_{\mathrm{Mn}}$ 浓度 有较明显的稀释作用,而降水量特少的月份会使 浓度变大.

\section{2 气象条件对 $\mathrm{NH}_{3}-\mathrm{N} 、 \mathrm{TN}$ 的影响}

水体中 $\mathrm{NH}_{3}-\mathrm{N} 、 \mathrm{NO}_{3}^{-}-\mathrm{N}$ 是植物吸收的主要形 式 ${ }^{[10,21]}$. 温度和光照影响水生植物的光合作用和 生长, 温度高、日照时数长、光照强, 水生植物生长 旺盛,吸收、降解水体中的氮就多,使得水体中氮 浓度下降. 3 月份以后随着气温回升、日照时数增 多, 水生植物进人生长季节, 对 $\mathrm{NH}_{3}-\mathrm{N} 、 \mathrm{TN}$ 的吸收 量增加,使 $\mathrm{NH}_{3}-\mathrm{N}$ 、TN 浓度下降; 夏季水生植物生 长旺盛, 对氮的吸收量大, 使 $\mathrm{NH}_{3}-\mathrm{N} 、 \mathrm{TN}$ 浓度处于

表 4 降水量特多和特少月份的 $\mathrm{COD}_{\mathrm{Mn}}$

Tab.4 Variation of $\mathrm{COD}_{\mathrm{Mn}}$ in particularly much and very little precipitation

\begin{tabular}{lcccc}
\hline 降水特征 & 年-月 & $\begin{array}{c}\text { 降水量/ } \\
\mathrm{mm}\end{array}$ & $\begin{array}{c}\mathrm{COD}_{\mathrm{Mn}} / \\
(\mathrm{mg} / \mathrm{L})\end{array}$ & $\begin{array}{c}\text { 与上月相比/ } \\
(\mathrm{mg} / \mathrm{L})\end{array}$ \\
\hline 降水特多 & $2008-6$ & 293.9 & 5.76 & -0.05 \\
降水特多 & $2009-7$ & 323.4 & 4.33 & -1.40 \\
降水特多 & $2009-8$ & 206.3 & 4.52 & +0.19 \\
降水特多 & $2010-3$ & 190.3 & 3.93 & -0.52 \\
降水特多 & $2010-7$ & 179.9 & 4.35 & -1.22 \\
降水特多 & $2011-6$ & 280.3 & 4.19 & -0.43 \\
降水特多 & $2013-10$ & 284.1 & 3.98 & -1.48 \\
降水特多 & $2014-6$ & 223.3 & 4.58 & -0.94 \\
降水特少 & $2007-1$ & 44.3 & 7.71 & +2.04 \\
降水特少 & $2007-4$ & 87.8 & 7.81 & +1.71 \\
降水特少 & $2007-5$ & 36.4 & 10.00 & +2.19 \\
降水特少 & $2008-4$ & 52.0 & 6.04 & +0.90 \\
降水特少 & $2009-9$ & 79.5 & 6.52 & +1.00 \\
降水特少 & $2010-6$ & 69.5 & 5.57 & +0.28 \\
降水特少 & $2013-11$ & 11.5 & 5.01 & +1.03 \\
降水特少 & $2014-10$ & 38.6 & 5.20 & +1.20 \\
\hline
\end{tabular}

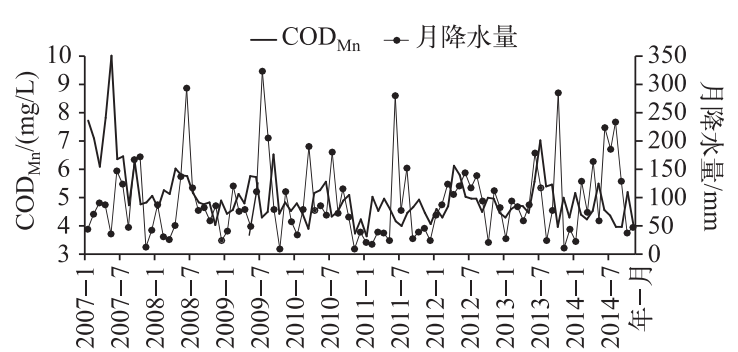

图 3 淀山湖 $\mathrm{COD}_{\mathrm{Mn}}$ 与降水量的月变化

Fig.3 Monthly variation of $\mathrm{COD}_{\mathrm{Mn}}$ with precipitation in Lake Dianshan 
低值时段; 而秋季后随着气温下降、日照时数减少, 水生植物生长趋缓, 对氮的吸收量减弱, 使 $\mathrm{NH}_{3}-\mathrm{N} 、 \mathrm{TN}$ 浓 度上升,到 2-3 月前后达到高值时段. 据研究, 太湖换水周期约为 $250 \mathrm{~d}^{[30]}$, 淀山湖换水周期约为 $28 \mathrm{~d}^{[31-32]}$. 流人淀山湖的水经过人湖河流千灯浦、大朱厍、急水港和元荡湖, 期间有数天时间; 其中部分水在太湖停留 一段时间后,再由东太湖经汾湖等多个湖荡后流进千灯浦、大朱厍、急水港和元荡湖等人湖河流, 经过的时 间更长; 流人淀山湖的水还要停留约 $28 \mathrm{~d}$; 前后时间跨度 $1 \sim 2$ 个月, 甚至更长. 在这 $1 \sim 2$ 个月中, 温度和日 照影响水生植物的生长, 从而影响对氮的吸收, 降水在稀释淀山湖水体中 $\mathrm{NH}_{3}-\mathrm{N} 、 \mathrm{TN}$ 浓度时同样稀释上游 太湖、汾湖、元荡湖等湖荡及千灯浦、大朱厍、急水港等河流中的 $\mathrm{NH}_{3} \mathrm{-N} 、 \mathrm{TN}$ 浓度, 降低流人淀山湖水体中的 $\mathrm{NH}_{3}-\mathrm{N} 、 \mathrm{TN}$ 浓度, 使淀山湖水体中 $\mathrm{NH}_{3}-\mathrm{N} 、 \mathrm{TN}$ 浓度降低. $\mathrm{NH}_{3}-\mathrm{N} 、 \mathrm{TN}$ 浓度高峰值出现在 2-4 月, 为冬末初春, 比一年中气温最低的 $1 、 2$ 月晚 1 2 个月; 低值出现在 7-10 月, 为夏季到初秋, 比气温最高的 7、8 月也晚 $0 \sim 2$ 个月; 降水量明显偏多的月份或后 $1 \sim 2$ 个月 $\mathrm{NH}_{3}-\mathrm{N} 、 \mathrm{TN}$ 浓度出现低值, 而降水量明显偏少的月份或后 $1 \sim 2$ 个月 $\mathrm{NH}_{3}-\mathrm{N} 、 \mathrm{TN}$ 浓度明显上升. 因此当月、上月和上 2 个月的平均气温、降水量、日照时数会影响 $\mathrm{NH}_{3}-\mathrm{N}$ 、 $\mathrm{TN}$ 浓度变化( 图 4).
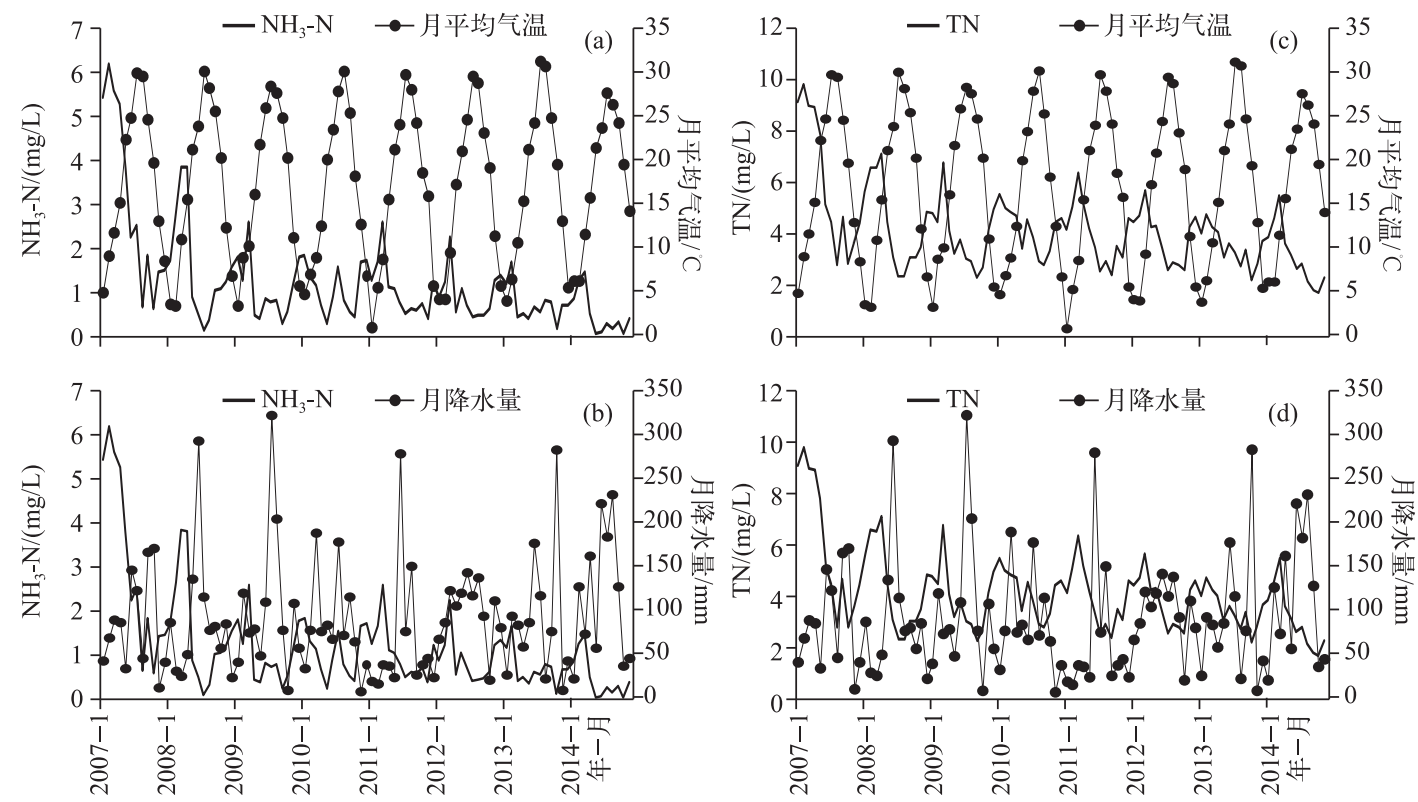

图 4 淀山湖 $\mathrm{NH}_{3}-\mathrm{N}(\mathrm{a} 、 \mathrm{~b}) 、 \mathrm{TN}(\mathrm{c} 、 \mathrm{~d})$ 与平均气温、降水量的月变化

Fig.4 Monthly variations of $\mathrm{NH}_{3}-\mathrm{N}(\mathrm{a}, \mathrm{b}), \mathrm{TN}(\mathrm{c}, \mathrm{d})$ concentrations with mean temperature and precipitation in Lake Dianshan

研究发现, 月降水量 $\geqslant 200 \mathrm{~mm}$ 的月份或连同上月降水量 $\geqslant 280 \mathrm{~mm}$ 的月份, 则 $\mathrm{NH}_{3}-\mathrm{N} 、 \mathrm{TN}$ 浓度明显下 降, $\mathrm{NH}_{3}-\mathrm{N}$ 浓度 $\leqslant 0.8 \mathrm{mg} / \mathrm{L}, \mathrm{TN}$ 浓度 $\leqslant 3 \mathrm{mg} / \mathrm{L}$. 而连续数月降水量少, $\mathrm{NH}_{3}-\mathrm{N} 、 \mathrm{TN}$ 浓度较高, 如 2008 年 2-4 月 3 个月降水量平均为 $111.9 \mathrm{~mm}$, 同期 $\mathrm{NH}_{3}-\mathrm{N}$ 浓度分别为 $2.67 、 3.84$ 和 $3.83 \mathrm{mg} / \mathrm{L}, \mathrm{TN}$ 浓度 $>5.6 \mathrm{mg} / \mathrm{L}$. 因 此, 降水对水体中 $\mathrm{NH}_{3}-\mathrm{N} 、 \mathrm{TN}$ 的稀释作用远远大于降水所形成的径流而进人河流或湖泊的 $\mathrm{NH}_{3}-\mathrm{N} 、 \mathrm{TN}$, 降水 量多, 稀释作用强, $\mathrm{NH}_{3}-\mathrm{N} 、 \mathrm{TN}$ 浓度低, 相反 $\mathrm{NH}_{3}-\mathrm{N} 、 \mathrm{TN}$ 浓度高(图 4).

\section{3 气象条件对 TP 浓度的影响}

温度高会增强微生物的活性从而促进底泥中内源磷的释放, 温度越高 TP 释放通量越大; 而水生植物对 磷的吸收、降解远低于对氮的吸收、降解 ${ }^{[2-25]}$. 因此温度高, TP 浓度就高; 相反温度低, TP 浓度就低. TP 浓度 高峰值出现在一年中平均气温最高的 7-8 月 (图 5).

许梅等 ${ }^{[10]}$ 认为, 磷在水中的浓度一般比较低, 主要吸附于土壤颗粒中, 降雨、开沟排水等会产生地表径流, 使营养丰富的表土层被侵蚀而进人河流, 从而使水体含磷量增加; 而降雨较少的时期,对土壤的冲刷作用也较 


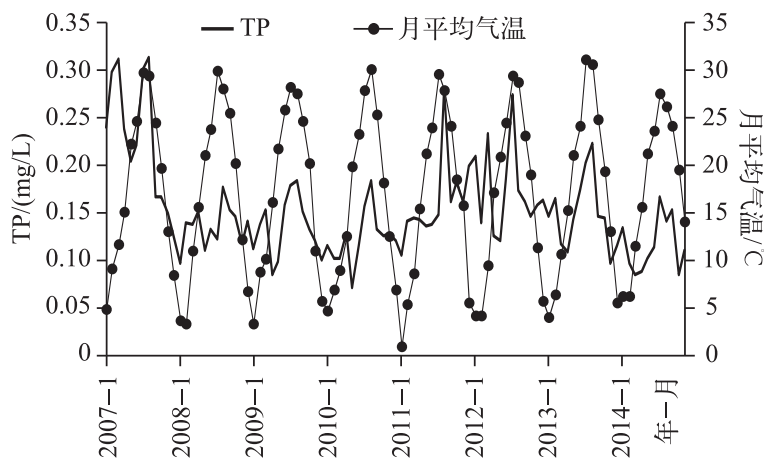

图 5 淀山湖 TP 浓度与平均气温的月变化

Fig.5 Monthly variations of TP concentration with mean temperature in Lake Dianshan

弱, 流失人湖的土壤颗粒较少, 水体含磷量也较低. 刘梅等 ${ }^{[16]}$ 认为降水少致径流减少, 径流的减少降低了水体 的稀释能力, 对磷而言径流的减少将会减少陆地磷污染物进人水体. 本文中, 尽管总磷浓度与降水量相关性不 显著, 但降水量偏多的月份 $(\geqslant 180 \mathrm{~mm})$, TP 浓度偏高,一般 $\geqslant 0.15 \mathrm{mg} / \mathrm{L}$; 降水量偏少的月份 $(\leqslant 100 \mathrm{~mm})$, TP 浓度偏高、偏低的情况都有, 而 TP 浓度 $\leqslant 0.10 \mathrm{mg} / \mathrm{L}$ 的月份, 月降水量基本上是偏少的月份 ( $\leqslant 100 \mathrm{~mm}$ ).

\section{5 小结}

1) 气象条件影响淀山湖湖体水质. 平均气温、日照时数影响 $\mathrm{NH}_{3}-\mathrm{N} 、 \mathrm{TN}$ 和 TP 浓度, 平均气温高、日照时 数多, $\mathrm{NH}_{3}-\mathrm{N} 、 \mathrm{TN}$ 浓度降低, 相反平均气温低、日照时数少, $\mathrm{NH}_{3}-\mathrm{N} 、 \mathrm{TN}$ 浓度升高; 平均气温高, 也会使 $\mathrm{TP}$ 浓 度上升, 平均气温低, $\mathrm{TP}$ 浓度降低. 降水对水体中 $\mathrm{COD}_{\mathrm{Mn}} 、 \mathrm{NH}_{3}-\mathrm{N}$ 和 $\mathrm{TN}$ 浓度有稀释作用, 降水量多的月份, 浓度偏低,相反,降水量少的月份浓度偏高. 降水量多的月份,TP 浓度偏高.

2) 受气象条件影响, $\mathrm{COD}_{\mathrm{Mn}} 、 \mathrm{NH}_{3}-\mathrm{N} 、 \mathrm{TN}$ 和 TP 有季节变化. $\mathrm{COD}_{\mathrm{Mn}}$ 农度 4-9 月较高, 10 月一翌年 3 月较 低; $\mathrm{NH}_{3}-\mathrm{N} 、 \mathrm{TN}$ 浓度最高时段 2-4 月前后, 7-10 月为最低时段; TP 浓度最高值出现在 7-8 月,最低值出现 在 10 月一翌年 5 月.

3)气温、光照、降水等气象因子通过影响水体中污染物来源、迁移转化方式、生化反应速率和生态效应 等过程而直接或间接地影响水质, 本文研究对上游来水带来污染和本地工业污染、农业农村面源污染、城镇 污染等排放的平原地区浅水、淡水湖泊有一定借鉴作用.

4) 所用的水质、气象资料为月资料,难以反映水质的变化过程. 随着淀山湖水文水质自动监测系统的建 成, 可以从日、时等更细的时间尺度研究气温、光照、降水、风等气象因子对水质的影响程度, 定量研究各水 质指标对气象因子变化的敏感性. 另一方面,气候变化引起气温上升、暴雨和干旱等极端天气事件, 分析研 究气候变化对湖泊水质、水生态环境影响程度,建立相应的预测、预警机制.

\section{6 参考文献}

[ 1 ] Gao Wei, Chen Yan, Xu Min et al. Trend and diving factors of water quality change in Lake Fuxian( $1980-2011)$. J Lake Sci, 2013, 25(5) :635-642 (in Chinese with English abstract). DOI: 10.18307/2013.0503. [高伟, 陈岩, 徐敏等. 抚仙 湖水质变化 (1980-2011) 趋势及驱动力分析. 湖泊科学, 2013, 25(5): 635-642.]

[ 2 ] Li Kun, Wang Ling, Li Zhaohua et al. Spatial variability characteristics of water quality and Its diving forces in Honghu Lake during high water-level period. Environmental Science, 2015, 36(4) : 1285-1292( in Chinese with English abstract). [李昆, 王玲, 李兆华等. 丰水期洪湖水质空间变异特征及驱动力分析. 环境科学, 2015, 36(4) : 1285-1292.]

[ 3 ] Chen Xiaoling, Zhang Yuan, Zhang Li et al. Distribution characteristic of nitrogen and phosphorus in Lake Poyang during high water period. J Lake Sci, 2013, 25 (5) : 643-648 (in Chinese with English abstract). DOI : 10.18307/2013.0504. [陈晓玲，张媛，张俐等. 丰水期鄱阳湖水体中氮、磷含量分布特征. 湖泊科学，2013，25(5): 643-648.]

[ 4 ] Li Yiping, Pang Yong, Xiang Jun. Analysis to the characteristics of temporal and spatial distribution of the pollutant and 
the law of release from sediment in Taihu Lake. Acta Scientiae Circumstantiae, 2005, 25(3) : 300-306 (in Chinese with English abstract). [ 李一平, 逢勇, 向军. 太湖水质时空分布特征及内源释放规律研究. 环境科学学报, 2005,25 (3) : 300-306.]

[ 5 ] Li Yufeng, Liu Hongyu, Cao Xiao. Characteristics of temporal and spatial distribution of water quality in urban wetland of the Xixi National Wetland Park, China. Environmental Science, 2010, 31(9) : 2036-2041 (in Chinese with English abstract). [ 李玉凤, 刘红玉, 曹晓. 西溪国家湿地公园水质时空分异特征研究. 环境科学, 2010, 31 (9): 2036-2041.]

[ 6 ] Hu Kaiming, Li Bing, Wang Shui et al. Spatial distribution characteristics of water quality pollution in the Lake Taihu basin, Jiangsu province. J Lake Sci, 2014, 26 (2) : 200-206 (in Chinese with English abstract). DOI: 10.18307/2014. 0205. [胡开明, 李冰, 王水等. 太湖流域 (江苏省) 水质污染空间特征. 湖泊科学, 2014, 26(2) : 200-206.]

[ 7 ] Wu Shirong, Xu Mengjia, Zhao Yanwei et al. Correlation between water quality and aquatic life in Baiyangdian wetland. Acta Scientiae Circumstantiae, 2013, 33(11): 3160-3165(in Chinese with English abstract). [武士蓉, 徐梦佳, 赵彦伟 等. 白洋淀湿地水质与水生物相关性研究. 环境科学学报, 2013, 33(11): 3160-3165.]

[ 8 ] Fang Xiaobo, Luo Linping, Li Song et al. Seasonal variations and source identification of surface water quality in Lanxi segment of Qiantang River. Acta Scientiae Circumstantiae, 2013, 33(7) : 1980-1988 (in Chinese with English abstract). [ 方晓 波, 骆林平, 李松等. 钱塘江兰溪段地表水质季节变化特征及源解析. 环境科学学报, 2013, 33(7): 1980-1988.]

[ 9 ] Sheng Haiyan, Wu Zhixu, Liu Mingliang et al. Water quality trends in recent 10 years and correlation with hydro-meteorological factors in Xin'anjiang Reservoir. Acta Scientiae Circumstantiae, 2015, 35(1) : 118-127(in Chinese with English abstract). [ 盛海燕, 吴志旭, 刘明亮等. 新安江水库近 10 年水质演变趋势及与水文气象因子的相关分析. 环境科 学学报, 2015, 35(1): 118-127.]

[10] Xu Mei, Ren Ruili, Liu Maosong. Annual changes of water quality in an upstream River of Taihu Lake. Journal of Nanjing Forestry University: Natural Sciences Edition, 2007, 31(6): 121-124(in Chinese with English abstract). [许梅, 任瑞 丽, 刘茂松. 太湖人湖河流水质指标的年变化规律. 南京林业大学学报: 自然科学版, 2007, 31(6): 121-124.]

[11] Liu Mei, Lü Jun. Response of river hydrology and water quality climate change in Changle River Watershed, Eastern China. Acta Scientiae Circumstantiae, 2015, 35(1): 108-117(in Chinese with English abstract). [刘梅, 吕军. 我国东部河 流水文水质对气候变化响应的研究. 环境科学学报, 2015, 35(1): 108-117.]

[12] Yin Daqiang, Qin Qiurong, Yan Hang. Effects of environmental factors on release of phosphorus from sediments in Wuli Lake. J Lake Sci, 1994, 6( 3) : 240-244(in Chinese with English abstract). DOI: 10.18307/1994.0307. [尹大强, 覃秋 荣, 阎航. 环境因子对五里湖沉积物磷释放的影响. 湖泊科学, 1994, 6(3) : 240-244.]

[13] Su Lidan, Lin Weiqing, Yang Yifan. Fluxes of nitrogen and phosphorus releasing from sediment in Lake Dianshan. Shanghai Environmental Sciences, 2010, 29(5) : 197-201 (in Chinese with English abstract). [苏丽丹, 林卫青, 杨渏帆. 淀 山湖底泥氮磷释放通量研究. 上海环境科学, 2010, 29(5): 197-201.]

[14] Wang Rong, Huang Tianyin, Wu Wei. Different factors on nitrogen ang phosphorus self-purification ability from urban Guandu-Huayuan River. J Lake Sci, 2016, 28(1) : 105-113(in Chinese with English abstract). DOI: 10.18307/2016. 0112. [王蓉, 黄天寅, 吴玮. 典型城市河道氮、磷自净能力影响因素. 湖泊科学, 2016, 28(1) : 105-113.]

[15] Li Qiang, Tian Hua, Jiang Min et al. Community structure of zooplankton and influencing factors in Lake Dianshan of Shanghai. Journal of Hydroecology, 2015, 36(4) : 2868-2874( in Chinese with English abstract). [李强, 田华, 姜民等. 淀山湖浮游动物群落结构特征及其影响因子. 水生态学杂志, 2015, 36(4) : 2868-2874.]

[16] Wang Liqing, Xu Li, Lu Ziyuan et al. Dynamic of phytoplankton abundance and the relationship with environmental factors in Lake Dianshan, Shanghai. Environmental Science, 2011, 32(10): 69-77(in Chinese with English abstract). [王丽卿, 许莉, 卢子园等. 淀山湖浮游植物数量消长及其与环境因子的关系. 环境科学, 2011, 32 (10): 69-77.]

[17] Yu Ting, Dai Jingjun, Lei Lamei et al. Effects of temperature, irradiance and nitrate on the growth of Cylindrospermopsis raciborskii N8. J Lake Sci, 2014, 26(3) : 441-446( in Chinese with English abstract). DOI: 10.18307/2014.0315. [于 婷, 戴景峻, 雷腊梅等. 温度、光照强度及硝酸盐对拟柱狍藻 (Cylindrospermopsis raciborskii N8) 生长的影响. 湖泊科 学, 2014, 26(3): 441-446.]

[18] Zhang Yanqing, Yang Guijun, Qin Boqiang et al. Effect of light intensity on growth of Microcystis flos-aquae colonies size. J Lake Sci, 2014, 26(4) : 559-566(in Chinese with English abstract). DOI: 10.18307/2014.0410. [张艳晴, 杨桂军, 秦伯强等. 光照强度对水华微囊藻 (Microcystis flos-aquae) 群体大小增长的影响. 湖泊科学, 2014, 26 (4): 559-566.] 
[19] Xia Xinghui, Wu Qiong, Mou Xinli. Advances in impacts of climate change on surface water quality. Advances in Water Science, 2012, 23(1): 125-133 (in Chinese with English abstract). [夏星辉, 吴琼, 牟新利. 全球气候变化对地表水 环境质量影响研究进展. 水科学进展, 2012, 23(1): 125-133.]

[20] Liu Jiankang ed. Advanced aquatic biology. Beijing: Science Press, 1999: 231-240(in Chinese). [刘建康. 高级水生生 物学. 北京: 科学出版社, 1999: 231-240.]

[21] Cui Lijuan, Li Wei, Zhang Manyin et al. Different wetland plant roles of removing nitrogen phosphorus on sewage water. $J$ Lake Sci, 2011, 22(2) : 203-208(in Chinese with English abstract). DOI : 10.18307/2011.0207. [崔丽娟, 李伟, 张曼 胤等. 不同湿地植物对污水中氮磷去除的贡献. 湖泊科学, 2011, 22(2) : 203-208.]

[22] Yang Danjing, Jing Yuanxiao, Chen Zhaoping et al. Study on removal effect and regulation of Cleistocalyx operculatu to N and P in eutrophic water body. Acta Scientiae Circumstantiae, 2012, 23 (18): 637-639(in Chinese with English abstract). [杨丹箐, 靖元孝, 陈兆平等. 水翁对富养化水体氮、磷去除效果及规律研究. 环境科学学报, 2012,23 (18) : 637-639.]

[23] Zhang Guilong, Zhao Jianning, Liu Hongmei et al. Kinetics of nitrate and ammonium uptake from eutrophic waters by different hydrophytes. J Lake Sci, 2013, 25(2) : 221-226(in Chinese with English abstract). DOI: 10.18307/2013.0207. [张贵龙, 赵建宁, 刘红梅等. 不同水生植物对富营养化水体无机氮吸收动力学特征. 湖泊科学, 2013, 25(2): 221-226.]

[24] Jin Shuquan, Zhou Jinbo, Zhu Xiaoli et al. Comparison of nitrogen and phosphorus uptake and water purification ability of ten aquatic macrophytes. Journal of Agro-Environment Science, 2010, 29(8) : 1571-1575(in Chinese with English abstract). [ 金树权, 周金波, 朱晓丽等. 10 种水生植物的氮磷吸收和水质净化能力比较研究. 农业环境科学学报, 2010, 29(8) : 1571-1575.]

[25] Wang Zhaohui, Jiang Tianjiu, Qi Sang et al. Studies of nitrogen and phosphorus removal capacity of Hydrodictyon reticulatum in eutrophic fresh water samples. Acta Scientiae Circumstantiae, 1999, 19(4) : 448-452(in Chinese with English abstract). [王朝晖, 江天久, 杞桑等. 水网藻 (Hydrodictyon reticulatum) 对富营养化水样中氮磷去除能力的研究. 环境 科学学报, 1999, 19(4): 448-452.]

[26] Wang Yan, Huang Jiacong, Yan Renhua et al. Nutrient removal efficiency of lake wetlands: A case study of Sanshan Wetland in Lake Taihu, eastern China. J Lake Sci, 2016, 28 (1): 124-131 (in Chinese with English abstract). DOI: 10. 18307/2016.0114. [王雁, 黄佳聪, 闻人华等. 湖泊湿地的水质净化效应一以太湖三山湿地为例. 湖泊科学, $2016,28(1): 124-131$.

[27] Wang Liqing, Li Yan, Zhang Ruilei. The purification of Lake Dianshan water quality with six species of submerged macrophytesystems. Journal of Agro-Environment Science, 2008, 27(3): 1134-1139(in Chinese with English abstract). [王丽卿, 李燕, 张瑞雷. 6 种沉水植物系统对淀山湖水质净化效果的研究. 农业环境科学学报, 2008, 27(3): 1134-1139.]

[28] Hua Chengping. Study on characteristics of seasonal variations with $\mathrm{COD}_{\mathrm{Mn}}$ in Changtan Reservoir, Zhejiang Province. Anhui Agricultural Science Bulletin, 2012, 23(18): 125-126(in Chinese with English abstract). [华呈平. 浙江省长潭水 库高锰酸盐指数季节变化特征研究. 安徽农业学报, 2012, 23(18): 125-126.]

[29] Cao Jinling, Xi Beidou, Xu Qigong et al. regional differences in physiographical, climatological and morphological effects on lake trophic status in China. Acta Scientiae Circumstantiae, 2012, 32(6) : 1512-1519(in Chinese with English abstract). [ 曹金玲, 席北斗, 许其功等. 地理气候及湖盆形态对我国湖泊营养状态的影响. 环境科学学报, 2012, 32 (6) : 1512-1519.]

[30] Chen Xiaohua, Li Xiaoping, Cheng Xi et al. Eutrophication evolution of typical small and medium-sized lakes in Lake Taihu basin(1991-2010). J Lake Sci, 2013, 25(6) : 846-853(in Chinese with English abstract). DOI: 10.18307/2013. 0608. [ 陈小华, 李小平, 程䂀等. 太湖流域典型中小型湖泊富营养化演变分析 (1991-2010 年). 湖泊科学, 2013, 25(6) : 846-853.]

[31] Ruan Renliang, Wang Yun. Study on assessment of water environmental quality and control of water pollution in Lake Dianshan, Shanghai. J Lake Sci, 1993, 5(2) : 153-158(in Chinese with English abstract). DOI: 10.18307/1993.0207. [ 阮 仁良, 王云. 淀山湖水环境质量评价及污染防治研究. 湖泊科学, 1993, 5(2)：153-158.]

[32] Zhao Zhen, Sun Congjun, Kang Lijuan et al. Studies on dynamic numerical simulation of water quality and integrated pollution control schemes for Lake Dianshan. Shanghai Environment Sciences, 2013, 32(3) : 103-112( in Chinese with English abstract). [ 赵振, 孙从军, 康丽娟等. 淀山湖水质动态数值模拟及污染治理方案研究. 上海环境科学, 2013, 32(3) : 103-112.] 